\title{
Selected Sociodemographic and Psychosocial Variables Related to Mothers' Preference for Childbirth Setting in a Barangay in Rosario, Cavite
}

\author{
Karell Jo Angelique C. Calpito, Charmaine M. Cañizares, Venice Ann Kaye R. Celis, Nover Edward P. Duarte, \\ Ma. Alea Razelle S. Gaela, John Robert C. Medina, Jonathan P. Guevarra and Ernesto R. Gregorio, Jr.
}

Department of Health Promotion and Education, College of Public Health, University of the Philippines Manila

\begin{abstract}
Objectives. This study aimed to describe selected sociodemographic and psychosocial factors that are related to mothers' preference for childbirth setting in a barangay in Rosario, Cavite.

Methods. This study utilized a descriptive cross-sectional design. An interview guide was developed, pretested, and used in interviewing mothers who had given birth from September 1, 2007 to August 31，2010. Data collected was encoded and analyzed using Epi-info 3.5.1 to compute for the means and proportions of relevant variables.

Results. A total of 271 mothers were interviewed, of whom $53.5 \%$ gave birth at health facilities. Mothers who were young adults, had at least graduated from high school, and/or had a family income of greater than Php 10,000 tended to prefer facilitybased delivery. Those who had adequate knowledge of child delivery and postpartum complications, as well as those with a positive attitude towards facility-based delivery, gave birth in health facilities. Among the family members, the spouses had greater influence on the decisions of mothers regarding their preference. Whereas doctors appeared to have influenced the decisions of mothers who had facility-based deliveries, midwives influenced those who had home-based deliveries.
\end{abstract}

Conclusion. The maternal mortality ratio in Rosario, Cavite and the facility-based delivery rate in the sampled barangay remain higher than the targeted rates. This necessitates more efforts to achieve Millennium Development Goal (MDG) No 5. The findings of this study can serve as a guide in developing health promotion and education intervention focusing on specific age group, significant others, and health providers in order to achieve the desired outcomes.

Key Words: childbirth, maternal health, facility-based delivery, home-based delivery, psychosocial variables

Corresponding author: Ernesto R. Gregorio, Jr., MPH

Department of Health Promotion and Education

College of Public Health

University of the Philippines Manila

625 Pedro Gil St. Ermita, Manila 1000 Philippines

Telephone: +6325260811

Email: jurgregorio@yahoo.com

\section{Introduction}

Improvement in maternal health is among the Millennium Development Goals (MDG) to be achieved before the end of 2015. In line with this, the Philippines has committed to reduce the maternal mortality ratio (MMR) in 1993 at 209 per 100,000 live births to 52 per 100,000 live births. ${ }^{1}$ However, the MMR in 2010 remained high at 230 per 100,000 live births, exceeding the 1993 Philippine data as well as data from the entire Western Pacific Region (82 per 100,000 live births). ${ }^{2,3}$ Several factors including low facilitybased birth deliveries may explain the slow decline in MMR. Facility-based deliveries refer to the proportion of deliveries in a health facilities where healthcare is delivered by trained healthcare providers.., 5

More than half of births in the Philippines are home deliveries and only $44 \%$ are reported to be facility-based. Of the latter, $27 \%$ occur in public facilities and $18 \%$ in private facilities. ${ }^{6}$ Deliveries supervised by qualified birth attendants were reported to be at $62 \% .^{2}$ Specifically, the delivery rates assisted by a doctor, a nurse or midwife, and a traditional birth attendant or hilot were $35 \%, 27 \%$, and $36 \%$, respectively. ${ }^{6}$ This data highlights the need for more efforts towards increasing the rate of facility-based delivery. ${ }^{6,7}$

Studies revealed that some family members such as spouses, mothers, and mothers-in-law, as well as healthcare providers influence a person's decision on the utilization of health services. ${ }^{8-11}$ In many extended families such as those in the Philippines, the mother's selection of setting for birth delivery appears to be formed from the different opinions of family members as opposed to being an individual decision. Thus, in addition to the mothers themselves, these "significant others" can be the focus of interventions that promote facility-based delivery. The influences of the aforementioned "significant others" on a person's behavior or decision are referred to as "reinforcing factors." However, there is a paucity of studies regarding these factors, with studies instead exploring "predisposing" and "enabling" factors. ${ }^{12-18}$

This study aimed to describe selected sociodemographic and psychosocial variables that may be related to mothers' preference of setting for childbirth by place of delivery in a barangay in Rosario, Cavite. Findings in this study may 
serve as basis for planning better health promotion interventions to improve maternal and child health. ${ }^{12}$

\section{Methods}

\section{Study Site}

The study was conducted in the municipality of Rosario, Cavite due to accessibility and the high ratio of maternal mortality at 125 per 100,000 live births, which was the third highest in the province. Health manpower included one doctor, 11 nurses, 19 midwives, 148 barangay health workers (BHWs), three dentists, and four sanitary inspectors. Specifically, Barangay Wawa III was selected on the recommendation of the chief nurse and midwife of the Municipal Health Office. The barangay had a total population of 8,743 and was subdivided into six sitios: Little Baguio, Sitio Banal, Bicol Region, Boracay, Aplaya/Breakwater, and Karla Ville. Barangay Wawa III was considered one of the depressed barangays of Rosario, Cavite.

\section{Study Design and Study Population}

This study used a descriptive cross-sectional design. The study population consisted of mothers who: 1) gave consent, 2) were residents of Barangay Wawa III, Rosario, Cavite, 3) and gave birth from September 1, 2007 to August 31, 2010. Simple random sampling was applied in selecting the target respondents at the community. A total of 271 mothers participated in the study.

\section{Research Instrument}

An interview guide was developed and reviewed by experts prior to use. It was pretested on 30 mothers who were residents of Barangay Ligtong IV, Rosario, Cavite who had given birth from September 1, 2007 to August 31, 2010. Some knowledge and attitude questions that were found unclear were revised accordingly.

The tool was divided into two components: the sociodemographic characteristics and the psychosocial variables based on the PRECEDE-PROCEED framework. The model was developed for planning health education and health promotion program. ${ }^{19}$ PRECEDE stands for Predisposing, Reinforcing, and Enabling Factors in Educational Diagnosis and Evaluation, whereas PROCEED refers to Policy, Regulatory, and Organizational Constructs in Educational and Environmental Development. To provide an evidence base for future health campaigns, educational assessment was performed. ${ }^{20}$ Educational assessment involves the determination of predisposing, reinforcing, and enabling factors. Predisposing factors refer to those that provide rationale for a behavior, such as knowledge, attitudes, beliefs, personal preferences, existing skills, and self-efficacy. ${ }^{20,21}$ In determining these factors, respondents were asked questions that measure knowledge and attitude.
The knowledge of the respondents was measured using nine yes/no questions pertaining to child delivery, complications associated with health provider-unattended home-based delivery, and the advantages of facility-based delivery. A point was given for each correct answer. A respondent was considered knowledgeable if at least $60 \%$ of her answers were correct. Meanwhile, the attitude of the respondents was measured using a four-point Likert Scale. For each statement, four points were ascribed to "strongly agree" and one point for "strongly disagree". An average score of at least three points was considered a favorable attitude.

Enabling factors include emotional, psychological or physical factors that allow productivity or realization of an aspiration. ${ }^{20,21,22}$ In this study, enabling factors were limited to physical factors such as accessibility or distance of respondent's home from a health facility. Accessibility was operationally defined as travelling at most 10 minutes away from home. Reinforcing factors refer to provision of reward, incentive or punishment that either promote or inhibit the persistence of a behavior..$^{20,21,22}$ To determine the effect of influence of the spouse, mother, mother-in-law, doctor, nurse, and midwife on the selection respondents regarding the setting of child delivery, five yes/no questions about each significant others were asked. At least $80 \%$ of the question (4 out of 5) should receive an affirmative answer from the respondent to indicate influence. A respondent may have indicated multiple "significant others".

\section{Data Collection, Management, and Analysis}

A guided face-to-face interview was conducted among the respondents from November 20, 2010 to December 17, 2010. Data collected was encoded and analyzed using EpiInfo 3.5.1 software. Descriptive statistics was employed in determining the proportions of the parameters.

\section{Ethical Considerations}

Assurance was provided that this study had followed a technically and ethically sound protocol. No more than minimal harm, if any, was imparted to the respondents. The objectives and procedures of the study were explained to the municipal, barangay authorities, and respondents from the selected site, and their approval was obtained. Written informed consent was obtained from the respondents without coercion or undue inducement. Codes were used to ensure confidentiality of information.

\section{Results}

\section{Sociodemographic Profile}

A total of 271 mothers were interviewed. A little more than half $(53.5 \%)$ had facility-based delivery while the rest (46.5\%) had home-based delivery from September 1, 2007 to August 31, 2010. Most were 22-27 years of age, with a small number of respondents $40-45$ years of age. The mean age in 
years of the respondents who had facility-based delivery was $29 \pm 5.5$, while those who had home-based delivery was $29 \pm 6.08$. A similar pattern of distribution was observed when the respondents were grouped according to place of delivery. It is noteworthy that a few more respondents $(10.3 \%)$ who had home deliveries were younger (16 to 21 ) compared to those who delivered at health facilities $(6.2 \%)$ (Table 1).

Table 1. Distribution of respondents according to age group and the setting of child delivery

\begin{tabular}{ccccccc}
\hline \multirow{2}{*}{ Age Group } & \multicolumn{2}{c}{$\begin{array}{c}\text { Facility-based } \\
\text { delivery } \\
(\mathbf{n = 1 4 5 )}\end{array}$} & \multicolumn{2}{c}{$\begin{array}{c}\text { Home-based } \\
\text { delivery } \\
(\mathbf{n = 1 2 6})\end{array}$} & \multicolumn{2}{c}{$\begin{array}{c}\text { Overall } \\
(\mathbf{n}=\mathbf{2 7 1})\end{array}$} \\
\cline { 2 - 7 } & No. & \% & No. & \% & No. & \% \\
\hline $16-21$ & 9 & 6.2 & 13 & 10.3 & 22 & 8.1 \\
$22-27$ & 59 & 40.7 & 44 & 34.9 & 103 & 38.0 \\
$28-33$ & 46 & 31.7 & 41 & 32.5 & 87 & 32.1 \\
$34-39$ & 25 & 17.2 & 22 & 17.5 & 47 & 17.3 \\
$40-45$ & 6 & 4.1 & 6 & 4.8 & 12 & 4.4 \\
\hline
\end{tabular}

The largest percentage of respondents (37.3\%) reported a monthly family income of Php 6,500 or below while a very few $(3.3 \%)$ reported greater than Php 20,000. Among those who had facility-based delivery, $36 \%$ reported a monthly family income of Php 6,500 or below, while only 3\% reported greater than Php 20,000. On the other hand, $42 \%$ of the respondents who delivered at home reported a monthly family income of greater than Php 6,500 but not more than Php 10,000. More respondents who had facility-based delivery had monthly family incomes from Php 10,001 to 20,000 (Table 2).

Table 2. Distribution of respondents according to income and the setting of child delivery

\begin{tabular}{lcccccc}
\hline Income (Php) & \multicolumn{2}{c}{$\begin{array}{c}\text { Facility-based } \\
\text { delivery } \\
(\mathbf{n = 1 4 5 )}\end{array}$} & \multicolumn{2}{c}{$\begin{array}{c}\text { Home-based } \\
\text { delivery } \\
(\mathbf{n}=\mathbf{1 2 6})\end{array}$} & \multicolumn{2}{c}{$\begin{array}{c}\text { Overall } \\
(\mathbf{n}=\mathbf{2 7 1})\end{array}$} \\
\cline { 2 - 7 } & No. & $\mathbf{\%}$ & No. & $\mathbf{\%}$ & No. & \% \\
\hline $0-6,500$ & 52 & 35.9 & 49 & 38.9 & 101 & 37.3 \\
$6501-10,000$ & 47 & 32.4 & 53 & 42.1 & 100 & 36.9 \\
$10,001-20,000$ & 41 & 28.3 & 20 & 15.9 & 61 & 22.5 \\
$\geq 20,001$ & 5 & 3.4 & 4 & 3.2 & 9 & 3.3 \\
\hline
\end{tabular}

Almost half of the respondents were high school graduates, 3\% were vocational school graduates, 10\% college graduates, and $4 \%$ had never attended school. It is noteworthy that a very high proportion of respondents $(>80 \%)$ who delivered at health facilities had at least graduated from high school compared to only $62 \%$ of those who delivered at home (Table 3).
Table 3. Distribution of respondents according to educational attainment and the setting of child delivery

\begin{tabular}{|c|c|c|c|c|c|c|}
\hline \multirow[t]{2}{*}{ Educational Attainment } & \multicolumn{2}{|c|}{$\begin{array}{c}\text { Facility- } \\
\text { based } \\
\text { delivery } \\
(\mathrm{n}=145)\end{array}$} & \multicolumn{2}{|c|}{$\begin{array}{c}\text { Home- } \\
\text { based } \\
\text { delivery } \\
(\mathrm{n}=126)\end{array}$} & \multicolumn{2}{|c|}{$\begin{array}{l}\text { Overall } \\
(n=271)\end{array}$} \\
\hline & No. & $\%$ & No. & $\%$ & No. & $\%$ \\
\hline Never attended school & 3 & 2.1 & 8 & 6.4 & 11 & 4.1 \\
\hline $\begin{array}{l}\text { Elementary school } \\
\text { graduate }\end{array}$ & 9 & 6.2 & 11 & 8.7 & 20 & 7.4 \\
\hline High school level & 13 & 9.0 & 29 & 23.0 & 42 & 15.5 \\
\hline High school graduate & 77 & 53.1 & 51 & 40.5 & 128 & 47.2 \\
\hline College level & 20 & 13.8 & 14 & 11.1 & 34 & 12.5 \\
\hline College graduate & 18 & 12.4 & 10 & 7.9 & 28 & 10.3 \\
\hline $\begin{array}{l}\text { Vocational school } \\
\text { graduate }\end{array}$ & 5 & 3.5 & 3 & 2.4 & 8 & 3.0 \\
\hline
\end{tabular}

\section{Psychosocial Factors}

Predisposing Factors

Table 4 shows that a high proportion of respondents ( 93\%) were knowledgeable on child delivery, postpartum complications associated with deliveries unattended by skilled health providers, and advantages of health facilitybased deliveries. A similar pattern of distribution in terms of knowledge was observed when the respondents were classified according to place of delivery.

Table 4. Distribution of respondents according to having knowledge on facility-based delivery and setting of child delivery

\begin{tabular}{lcccccc}
\hline & $\begin{array}{c}\text { Facility-based } \\
\text { delivery } \\
(\mathbf{n}=\mathbf{1 4 5})\end{array}$ & $\begin{array}{c}\text { Home-based } \\
\text { delivery } \\
(\mathbf{n}=\mathbf{1 2 6})\end{array}$ & $\begin{array}{c}\text { Overall } \\
(\mathbf{n}=\mathbf{2 7 1})\end{array}$ \\
\cline { 2 - 7 } & No. & $\mathbf{\%}$ & No. & $\mathbf{\%}$ & No. & $\mathbf{\%}$ \\
\hline Knowledgeable & 137 & 94.5 & 116 & 92.1 & 253 & 93.4 \\
Not Knowledgeable & 8 & 5.5 & 10 & 7.9 & 18 & 6.6 \\
\hline
\end{tabular}

In terms of attitudes towards facility-based delivery, a high proportion of respondents $(95.2 \%)$ had a favorable attitude. Specifically, more respondents who delivered at health facilities $(98 \%)$ had a favorable attitude towards facility-based delivery compared to those who had delivered at home (92\%) (Table 5).

Table 5. Distribution of respondents according to their attitudes towards facility-based delivery and setting of child delivery

\begin{tabular}{lcccccc}
\hline & $\begin{array}{c}\text { Facility-based } \\
\text { delivery } \\
(\mathbf{n = 1 4 5})\end{array}$ & \multicolumn{2}{c}{$\begin{array}{c}\text { Home-based } \\
\text { delivery } \\
(\mathbf{n}=\mathbf{1 2 6})\end{array}$} & $\begin{array}{c}\text { Overall } \\
(\mathbf{n}=\mathbf{2 7 1})\end{array}$ \\
\cline { 2 - 7 } & No. & $\mathbf{\%}$ & No. & $\mathbf{\%}$ & No. & $\mathbf{\%}$ \\
\hline Favorable & 142 & 97.9 & 116 & 92.1 & 258 & 95.2 \\
Not Favorable & 3 & 2.1 & 10 & 7.9 & 13 & 4.8 \\
\hline
\end{tabular}




\section{Enabling Factors}

Of the total respondents, $74.2 \%$ reported living 10 minutes away from the nearest birth facility. The same pattern of distribution was observed when the respondents were divided into those who had facility-based delivery and home-based delivery (Table 6).

Table 6. Distribution of respondents according to the time and setting of child delivery

\begin{tabular}{lcccccc}
\hline & $\begin{array}{c}\text { Facility-based } \\
\text { delivery } \\
(\mathbf{n = 1 4 5 )}\end{array}$ & $\begin{array}{c}\text { Home-based } \\
\text { delivery } \\
(\mathbf{n}=\mathbf{1 2 6})\end{array}$ & $\begin{array}{c}\text { Overall } \\
(\mathbf{n}=\mathbf{2 7 1})\end{array}$ \\
\cline { 2 - 7 } & No. & $\mathbf{9}$ & No. & $\mathbf{\%}$ & No. & $\mathbf{\%}$ \\
\hline Within 10 minutes & 107 & 73.8 & 94 & 74.6 & 201 & 74.2 \\
More than 10 minutes & 38 & 26.2 & 32 & 25.4 & 70 & 25.8 \\
\hline
\end{tabular}

\section{Reinforcing Factors}

Of the respondents, $44.6 \%$ stated that their spouses had greater influence on their decision for their selection of setting for child birth than their mothers and mothers-inlaw. In terms of health providers, midwives were reported to have greater influence $(24.4 \%)$ than doctors and nurses. When respondents were classified according to the place of birth delivery, results showed that doctors had greater influence on the decision of mothers who had delivered at health facilities $(26.9 \%)$, while midwives had greater influence on the decision of mothers who had delivered at home $(27.8 \%)$ (Table 7$)$.

Table 7. Distribution of respondents according to the influence of significant others and setting of child delivery*

\begin{tabular}{lcccccc}
\hline & $\begin{array}{c}\text { Facility-based } \\
\text { delivery } \\
(\mathbf{n = 1 4 5 )}\end{array}$ & \multicolumn{2}{c}{$\begin{array}{c}\text { Home-based } \\
\text { delivery } \\
\text { (n=126) }\end{array}$} & $\begin{array}{c}\text { Overall } \\
(\mathbf{n}=\mathbf{2 7 1})\end{array}$ \\
\cline { 2 - 7 } & No. & \% & No. & \% & No. & \% \\
\hline Family Members & 70 & 48.3 & 51 & 40.5 & 121 & 44.6 \\
Spouse & 25 & 17.2 & 19 & 15.1 & 44 & 16.2 \\
Mother & 12 & 8.3 & 15 & 11.9 & 27 & 10.0 \\
Mother-in-law & & & & & & \\
& & & & & & \\
Health Providers & 39 & 26.9 & 12 & 9.5 & 51 & 18.8 \\
$\begin{array}{l}\text { Doctor } \\
\text { Nurse }\end{array}$ & 16 & 11.0 & 11 & 8.7 & 27 & 10.0 \\
Midwife & 31 & 21.4 & 35 & 27.8 & 66 & 24.4 \\
*Multiple response & & & & & & \\
\hline
\end{tabular}

\section{Discussion}

The results of this study revealed that Barangay Wawa III, Rosario, Cavite had a facility-based delivery rate of about $54 \%$, which was greater than the national average of $44 \%$. Although this appears favorable, this rate was still much lower than the national and regional target of $80 \% .^{4}$ In addition, the MMR in the municipality of Rosario remained high at 126 per 100,000 live births which was higher than the targeted goal of 52 per 100,000 by 2015. Further efforts are needed in order to achieve the target goal prior to the end of 2015.

Central to achieving the MDG target is to determine and later explore the possible reasons why many mothers in the locality remain adherent to home deliveries. Since demographic, economic, and psychosocial variables play crucial roles in health and health disparities,,$^{23,24,25}$ there was a need to identify which among these variables influenced mothers' selection of setting for delivery. This study was limited to the identification of patterns of distribution between these factors and the selection of place for delivery. Establishing a causal relationship was outside the scope of this descriptive study.

Another finding in this study was that more mothers in the younger age group (16 to 21) preferred home-based delivery than a facility-based one. This particular segment could have been influenced by their spouse or relatives in their preference for home delivery. Moreover, delivery by traditional birth attendants was still practiced in this depressed barangay. The age group included very young mothers who could be more prone to high-risk pregnancies secondary to their immature reproductive anatomy and physiology. The age group included adolescents who were not only at high risk for adverse pregnancy outcomes ${ }^{26,27,28}$ but could also be economically and socially disadvantaged. Several international agreements had emphasized the right of adolescents to access adequate reproductive health

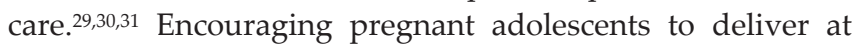
healthcare facilities through the necessary means is part of the duties and responsibilities of public health professionals. This finding also suggests the need to strengthen the provision of reproductive health services including health and sexuality education to significantly minimize, if not eliminate, teenage pregnancies in this barangay.

Only $4 \%$ of respondents belong to the older reproductive age group (40 to 45 years old). The same result was observed when the data was analyzed according to place of delivery. Although this figure was low, it was nevertheless important that reproductive and maternal health services address this gap because pregnant women who belong to this age group are also at high risk to pregnancy complications.

This study also found that as monthly family income increases, the number of mothers who decided to have a facility-based delivery tends to increase. The data showed that the family income may be related to selection of facilities for child birth. The study did not determine whether the health facility was private or public. However, it could be surmised that if the facility were private, having higher income might have influenced the selection of the facility for child birth. If the facility were public, family income might have influenced the selection in terms of availability of money for transportation to and from the health facilities and other related expenses. The above 
findings are consistent with studies which tried to establish a relationship between wealth-related variables and the utilization of maternal health services. ${ }^{32-35}$ Low utilization of maternal health services had been observed in areas where people had low income. ${ }^{32-35}$ However, those with income greater than Php 20,000 appeared to be an exemption from the trend observed in this study, since the proportions of those who had facility-based delivery and home-based delivery were almost equal. The homogeneity of the population in terms of economic status might explain the deviation of this finding from the pattern. Barangay Wawa III was one of the depressed barangays in Rosario, Cavite, where the majority of people lived in slums and were transient.

A high level of education entails utilization of maternal health services, including facility-based delivery. This observation from the study coincides with the findings in related studies, where maternal education was found to be a significant predictor of maternal use of health services. ${ }^{17,18,32-}$ ${ }^{37}$ In this study, there were more respondents who had at least a high school education among those who delivered at health facilities than among those who opted to deliver at home. This was consistent with the finding in a local study among Ifugaos in which a consistent increase in facilitybased deliveries was noted as the level of maternal education increased. ${ }^{35}$ This means that a high level of education was indeed a determinant of better health outcome including maternal health.

Since the long-term use of this study is to utilize the findings in designing health education and health promotion interventions, the PRECEDE-PROCEED framework was adopted to identify psychosocial factors that are related to mother's preference of childbirth setting. The findings could guide public health professionals in determining the reasons for underutilization of childbirth facilities.

Knowledge on child delivery, postpartum complications associated with unattended deliveries, and the advantages of facility-based deliveries was assessed in this study. The results showed that a higher proportion of mothers who delivered at health facilities were more knowledgeable, although the difference was small, compared to those who delivered at home. A higher proportion of respondents who delivered at health facilities expressed a more favorable attitude toward facility-based delivery compared to those who delivered at home. These results indicated that a high level of knowledge and a positive attitude of mothers could influence their choice of place for birth deliveries. This knowledge and attitude could also be related to their level of education and exposure to health messages delivered at the rural health units. This result is consistent with the findings of other studies. ${ }^{38,39,40}$ Further exploration of this area through a mixed method approach is recommended.

Studies had shown that the location and distance of a health facility could either serve as a motivating factor or a barrier for utilization of birthing facility.40,41,42 Thus, accessibility of a health facility, indicated by the time needed to travel, was included in this study as an enabling factor. The results of this study show that the proportion of those who live within 10 minutes from the nearest birthing facility were almost equal among those who had facility-based delivery and home-based delivery. The pattern contrasts that of a local study among Ifugaos, which showed an increase in the magnitude of association between the time needed to travel to the nearest birthing facility and the rate of facility-based delivery. ${ }^{35}$ Despite the strong association, the culture, geographical setting, and socioeconomic status of the two areas might provide an explanation for the variation.

Guided by the notion that marriage unites a man and a woman, there is a possibility that the husband may influence the decision of his spouse. This possibility can be related to the Filipino society's patriarchal nature. ${ }^{15}$ Thus, the influence of a husband was determined in this study. Results showed that husbands, more than the mother and mother-in-law, were found to have the greatest influence on the respondents' decision in terms of place of delivery. A qualitative study in Uganda, which had shown a similar observation, revealed that most of the mothers considered their husbands as the "money-maker," worthy of sharing in the decision process. Because having extended families is common in Filipino society, living with the in-laws is a typical set-up. The mother and/or the mother-in-law sometimes participates in decision-making processes, including concerns regarding childbirth. ${ }^{15}$ However, no evidence of such phenomenon was found in this particular study. A more in-depth qualitative study can be performed to explain this finding.

This study showed that doctors influenced the decision of those who delivered at the health facilities while midwives influenced the selection for home-based delivery. Higher level of education and income of those who delivered at the health facilities could be one of the explanations for this finding. Preference for home delivery could have been influenced by several factors: private practice of the midwives which encourages home delivery, common perception that delivery at health facilities is more expensive, and personal relation established between the pregnant women and the midwives.

\section{Conclusion}

The MMR in the municipality of Rosario, Cavite, as well as the rate of facility-based delivery, remain far from the national targets. Greater effort is needed in order to attain this goal prior to the end of 2015. This study showed that more respondents who were 21 years old or younger, with low family income, who did not graduate from high school preferred to deliver at home. A slightly higher proportion of respondents who were knowledgeable about and had a 
favorable attitude toward facility-based delivery gave birth in health facilities. Spouses and doctors exerted influence in mothers' preference for facility-based delivery.

\section{Recommendations}

To increase the facility-based deliveries in this barangay, health education messages should be tailored to certain demographic and psychosocial variables established in this study. There is a need to develop reproductive health messages specific to the very young (16 to 21 year old) and old (40 to 45 year old) mothers as these age groups are more prone to high-risk pregnancy. There is also a need to include the spouses of pregnant women in the local government unit's reproductive health program as they exert an influence on their partners' choice of facility for child birth. Health providers such as doctors, nurses, and midwives had to be reminded of the influence that they exert on mothers' selection of facilities for child birth. Further studies that will establish statistical association of the different variables as well as including other reinforcing and enabling variables are also recommended.

\section{Limitations}

The above-mentioned conclusion and recommendations should be interpreted in light of the study's limitations. While efforts were made to reduce systematic error in the study, there is the possibility of recall bias when the respondents were asked to recall study-related information from the past 3 years. Social desirability bias may have also been introduced during the interviews. Furthermore, the results may only be generalizable to Barangay Rosario which was chosen for its accessibility compared to other barangays. The study only described selected demographic and psychosocial variables in terms of place of delivery. Determining whether the differences observed were statistically significant or whether a variable was a predictor of the preference for place of delivery was beyond the scope of the study.

\section{References}

1. United Nations Development Program. Millennium Development Goals [Online]. 2010 [cited 2014 March]. Available from http://www.undp.org.ph/?link=goal_5

2. World Health Organization. World Health Statistics 2010 [Online]. 2010 [cited 2014 March]. Available from [http://www.who.int/whosis/whostat/EN_WHS10_Full.pdf]

3. Integrated Regional Information Networks (IRIN). Philippines: Maternal mortality rates not making sufficient progress. UNHCR [Online]. 2009 [cited $2014 \quad$ March]. Available from http://www.unhcr.org/refworld/docid/49cb32fcc.html

4. Department of Health. Maternal, Newborn and Child Health and Nutrition (MNCHN) Strategy Manual of Operations, $2^{\text {nd }}$ ed. 2011.

5. Moyer CA. Facility-based delivery in Ghana: A three-part study of drivers and deterrents [Online]. 2012 [cited 2014 March]. Available from http://deepblue.lib.umich.edu/handle/2027.42/96081
6. National Statistics Office (Philippines), ICF Macro. National Demographic and Health Survey 2008. 2009. Calverton, Maryland: National Statistics Office and ICF Macro.

7. Mercado D. Level of Awareness and Preventive Practices on Complications of Home Delivery of Selected Women in Cagayan de Oro City. Japan Philippine Association of Institutions for Research. 2008. 1 (1).

8. Amooti-Kaguna B, Nuwaha F. Factors influencing choice of delivery sites in Rakai district of Uganda. Soc Sci Med. 2000; 50(2):203-13.

9. Hazemba AN, Siziya S. Choice of place for childbirth: prevalence and correlates of utilization of health facilities in Chongwe district, Zambia. Medical Journal of Zambia. 2003; 35(2):53-7.

10. Salako AA, Oloyede OA, Odusoga OL. Factors influencing nonutilization of maternity care services in Sagamu, South Western Nigeria. Trop J Obstet Gynaecol. 2006; 23(1):48-53.

11. Simkhada B, Porter MA, van Teijlingen ER. The role of mothers-in-law in antenatal care decision-making in Nepal: a qualitative study. BMC Pregnancy Childbirth. 2010; 10:34.

12. Chakraborty N, Islam MA, Chowdhury RI, Bari W, Akhter HH. Determinants of the use of maternal health services in rural Bangladesh. Health Promot Int. 2003; 18(4):327-37.

13. Wagle RR, Sabroe S, Nielsen BB. Socioeconomic and physical distance to the maternity hospital as predictors for place of delivery: an observation study from Nepal. BMC Pregnancy Childbirth. 2004; 4(1):8.

14. Das S, Bapat U, More NS, Chordhekar L, Joshi W, Osrin D. Prospective study of determinants and costs of home births in Mumbai slums. BMC Pregnancy Childbirth. 2010; 10:38.

15. Titaley CR, Hunter CL, Dibley MJ, Heywood P. Why do some women still prefer traditional birth attendants and home delivery?: a qualitative study on delivery care services in West Java Province, Indonesia. BMC Pregnancy Childbirth. 2010; 10:43.

16. Giacaman R, Abu-Rmeileh NM, Wick L. The limitations on choice: Palestinian women's childbirth location, dissatisfaction with the place of birth and determinants. Eur J Public Health. 2007; 17(1):86-91.

17. Navarro A. The Utilization of Maternal Health Care Services in Various Health Care Settings in Vigan City. Vigan City: University of Northern Philippines.2001.

18. Rogan S, Olveña V. Factors Affecting Maternal Health Utilization in the Philippines [Online]. 2004 [cited 2014 March]. Available from http://www.nscb.gov.ph/ncs/9thncs/papers/health_Factors.pdf

19. Green LW, Kreuter, MW, Deeds SG, Partridge KB. Health Education Planning: A Diagnostic Approach. Mountain View, CA: Mayfield Publishers; 1980.

20. Ransdell LB. Using the PRECEDE-PROCEED Model to increase productivity in health education faculty. Int Electron J Health Educ. $2001 ; 4: 276-82$.

21. Stathopoulou HG, Skourti IG. Health care workers' participation in influenza vaccination programs.Application of the PRECEDEPROCEED model. Health Science Journal.2010; 4(3):142 -148.

22. Green LW, Kreuter MW. Health Promotion Planning: An Educational and Environmental Approach, $2^{\text {nd }}$ Ed. Mountain View, CA: Mayfield Publishers; 1991.

23. Martikainen P, Bartley M, Lahelma E. Psychosocial determinants of health in social epidemiology. Int J Epidemiol. 2002; 31(6):1091-3.

24. Braveman P. Accumulating knowledge on the social determinants of health and infectious disease. Public Health Rep. 2011; 126 Suppl 3:28 30 .

25. Lewis R, West L, Mazive E. Maternal mortality in Mozambique: Findings on the timing of death and the role of HIV/AIDS. 2011.

26. United Nations. The world's women, 1970-1990: trends and statistics. New York: United Nations, 1991.

27. Smith GC, Pell JP. Teenage pregnancy and risk of adverse perinatal outcomes associated with first and second births: population based retrospective cohort study. BMJ. 2001; 323(7311):476.

28. World Health Organization. The second decade: improving adolescent health and development. Geneva: World Health Organization, 2001.

29. UNICEF. The United Nations Convention on the Rights of the Child London: UNICEF UK, 1990.

30. UN. The Millennium Development Goals report 2011. New York: United Nations, 2011. 
31. UN Economic and Social Council. Commission on Population and Development: report on the forty-fifth session. New York: United Nations, 2012.

32. Babalola S, Fatusi A. Determinants of use of maternal health services in Nigeria - looking beyond individual and household factors. BMC Pregnancy Childbirth. 2009; 9:43.

33. Ahmed S, Creanga AA, Gillespie DG, Tsui AO. Economic status, education and empowerment: implications for maternal health service utilization in developing countries. PLoS One. 2010; 5(6): e11190.

34. Fotso JC, Ezeh A, Oronje R. Provision and use of maternal health services among urban poor women in Kenya: What do we know and what can we do? J Urban Health. 2008. 85(3):428-42.

35. Shimazaki A, Honda S, Dulnuan MM, Chunanon JB, Matsuyama A. Factors associated with facility-based delivery in Mayoyao, Ifugao Province, Philippines. Asia Pac Fam Med. 2013; 12(1):5.

36. Salako AA, Oloyede OA, Odusoga OL. Factors influencing nonutilization of maternity care services in Sagamu, South western Nigeria. Trop J Obstet Gynaecol. 2006; 23:48-53.

37. Gabrysch S, Campbell OM. Still too far to walk: literature review of the determinants of delivery service use. BMC Pregnancy Childbirth.2009; 9:34.
38. Mpembeni RN, Killewo JZ, Leshabari MT, et al. Use pattern of maternal health services and determinants of skilled care during delivery in Southern Tanzania: implications for achievement of MDG-5 targets. BMC Pregnancy Childbirth. 2007; 7:29.

39. Kruk ME, Rockers PC, Mbaruku G, Paczkowski MM, Galea S. Community and health system factors associated with facility delivery in rural Tanzania: A multilevel analysis. Health Policy. 2010; 97(2-3):20916.

40. Pfeiffer C, Mwaipopo R. Delivering at home or in a health facility? Health-seeking behaviour of women and the role of traditional birth attendants in Tanzania. BMC Pregnancy Childbirth. 2013; 13:55.

41. Sarr PT, Kasturiarachchi CJ, Yang He, et al. Investigating the motivating factors behind high delivery rates of the urban HEART birthing facility in San Martin de Porres, Philippines. Journal of the National Institute of Public Health. 2010; 59(1):64-70.

42. UNICEF-PIDS. Hilots getting on board facility-based deliveries. The Filipino child: Global Study on child poverty and disparities: Philippines. Policy Brief No. 1. 2010.

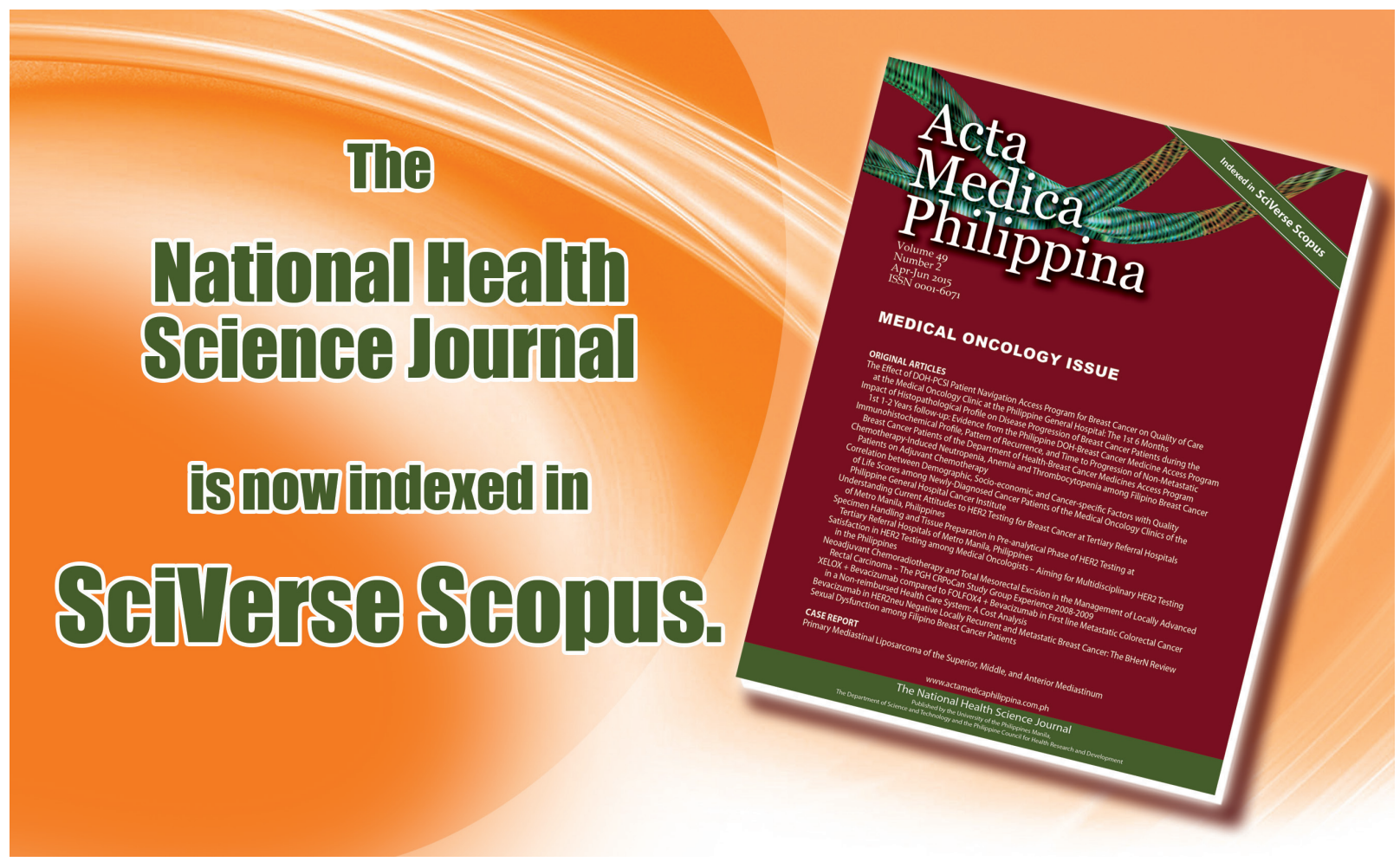

